\title{
REPRESENTAÇÃO SOCIAL DO TRABALHO EM EQUIPE NA ATENÇÃO À MULHER SOB A ÓTICA DA ENFERMEIRA
}

\author{
Social Representation of the Team Work in the Attention \\ to the Woman According to the Nurse's View \\ Representación Social del Trabaj o en Equipo en la \\ Atención a la Mujer Desde la Óptica de la Enfermera
}

Cássia Barbosa Reis ${ }^{1}$

Sônia Maria Oliveira Andrade²

\section{Resumo}

$\mathrm{Na}$ assistência à saúde da mulher, a realidade observada é de um atendimento fragmentado. Neste sentido, o estudo tem por objetivo conhecer a representação social das enfermeiras sobre o trabalho em equipe na assistência à mulher na rede básica. Foram realizadas entrevistas com enfoque qualitativo, baseadas na Teoria das Representações Sociais e analisadas através do Discurso do Sujeito Coletivo. Os resultados são apresentados em forma de discursos, tendo como eixo o sentido da equipe para a enfermeira. Esta tem uma visão fragmentada da assistência à saúde da mulher, ainda pautada nas queixas físicas; diz que trabalha em equipe, mas percebe que os profissionais não têm o mesmo objetivo e trabalham de forma individualizada. Ainda que perceba ser um elo de ligação entre os profissionais e os pacientes, sente que existe uma disputa de espaço/poder entre os profissionais.

Palavras-chave: Saúde da Mulher. Equipe de Assistência ao Paciente. Assistência à Saúde.

\begin{abstract}
In the attendance to the woman's health the reality observed is a fragmented attendance. In this sense, this research had the objective to know the social representation of the nurses on the work group in attendance to the woman in the basic net. It were realized interviews with a qualitative focalization, based on the Theory of Social Representations and analyzed by the Discourse of the Collective Subject. The results are presented in a discourse form built and having as a focal point the sense of the group to the nurse. The nurse has a fragmented vision of the attendance to the woman health, still regulated on physical complains; they say they work in group, but they notice that the professionals do not have the same objective and they work in an individualized form. Even if they notice it is a link of connection between professionals and patients, they feel there is a space/power dispute among the professionals.
\end{abstract}

Keywords:

Women Health. Patient Care Team. Delivery of Health Care.

\section{Resumen}

En la ayuda a la salud de la mujer la realidad observada está de una atención fragmentada. En esta dirección, este estudo tien como objetivo saber la representación social de las enfermeras en el trabajo en equipo en la ayuda a la mujer en la red básica. Las entrevistas con acercamiento cualitativo habían sido llevadas, basado en la teoría de las representaciones sociales y analizadas con el discurso del ciudadano colectivo. Los resultados se presentan en la forma de discursos, teniendo como árbol la dirección del equipo para la enfermera. Esta tiene una visión hecha fragmentos de la ayuda a la salud de la mujer, todavía pautada en las quejas físicas; dice que los trabajos son en equipo, pero percibe que los profesionales no tienen el mismo objetivo y trabajo de la forma individualizada. A pesar de eso percibe ser un acoplamiento del conectador entre los profesionales y los pacientes, se sienten que existe un conflicto del espaciopara poder entre los profesionales.

Palabras clave: Salud de la Mujer. Grupo de Atención al Paciente. Prestación de Atencíon de Salud. 


\section{INTRODUÇÃO}

Com a implantação dos princípios da reforma sanitária, iniciou-se a reorganização do modelo assistencial em saúde, cujas bases estão descritas no Manual para Organização da Atenção Básica ${ }^{1}$. Essa reorganização está pautada no modelo de vigilância em saúde, que tem como base a formação das equipes de saúde da família². Para que haja sucesso desta estratégia, espera-se que as equipes possam: 1) fazer 0 planejamento de acordo com o diagnóstico local detalhado para que as ações sejam efetivas; 2) trabalhar com o conceito positivo de saúde de forma a fazer a promoção e a vigilância à saúde; 3 ) desenvolver 0 espírito de trabalho interdisciplinar de forma a valorizar os diversos saberes e práticas na abordagem das famílias e 4) fazer uma abordagem integral da família.

Denominado Programa de Saúde da Família (PSF), passa a ter a família como foco de atenção na promoção da saúde e na prevenção de doenças, mas sem descuidar do indivíduo, assistido também nas áreas curativa, de tratamento e de reabilitação.

0 PSF é uma estratégia de mudança e implanta-se gradualmente nos estados e municípios desde 1994. Em se tratando de uma estratégia implantada em um país de dimensões continentais como o Brasil, entende-se que é um processo longo, permeado por avanços e retrocessos. 0 PSF está implantado em 4.646 municípios e em 97,4\% dos municípios do estado de Mato Grosso do Sul ${ }^{3}$. Entretanto, apesar das mudanças quantitativas já observadas, diversos estudos que compõem o diagnóstico da situação de saúde da mulher no Brasil ${ }^{4}$ apontam para a mesma conclusão de Pinto e Luiz $^{5}$, que mostrou não haver ampliação significativa da qualidade e acesso na atenção à saúde da mulher.

Um dos problemas apontados é que grande parte dos profissionais inseridos nas equipes de PSF não apresenta perfil para o trabalho preconizado nas diretrizes do programa. Isso leva a uma assistência não muito diferenciada do modelo centrado no médico e com baixa resolutividade.

Vale ressaltar que a evolução do SUS nos anos de 1980 e 1990 mostra o aumento do número de profissionais de enfermagem na rede de saúde nessas décadas ${ }^{6}$. Neste sentido, a enfermagem é resgatada como prática social, mostrando o seu desenvolvimento na relação com as outras profissões de saúde, especialmente a medicina e os modelos de assistência à saúde no Brasil .

As autoras das duas fontes citadas anteriormente reforçam, ainda, o enfoque de Schraiber ${ }^{8}$ na responsabilidade dos profissionais de saúde na construção do Sistema Único de Saúde (SUS) e colocam a integralidade da assistência à saúde como o maior desafio nas práticas de saúde na esfera das ações técnicas. Explicitam que, para atingir a integralidade da assistência no plano macro, um dos objetivos a perseguir é a integralidade da assistência no atendimento de cada profissional e no conjunto de cuidados desses profissionais a cada indivíduo e/ou comunidade.

Moretto ${ }^{9}$ discute a formação do enfermeiro frente ao SUS e analisa sua inserção na saúde pública sem o devido aparato teórico, e principalmente, prático. Enfoca também o papel do ensino de graduação na discussão da cidadania com os acadêmicos de forma que haja engajamento desses como parte integrante do coletivo.

Moscovici ${ }^{10}$ lista os componentes principais do funcionamento do grupo, que, em conjunto com os valores, as normas e os sentimentos individuais de seus integrantes, definirão a cultura, 0 clima, o comportamento e o desempenho grupal.

A presente pesquisa tem como objetivo descrever as representações sociais das enfermeiras sobre o trabalho em equipe nas unidades de saúde.

\section{METODOLOGIA}

Estudo qualitativo onde foi utilizada como técnica a estratégia da entrevista semi-estruturada, seguindo roteiro de entrevista que buscava entender o significado de equipe para as entrevistadas. A construção do roteiro foi fundamentado na Teoria das Representações Sociais (TRS), uma interpretação da realidade que pressupõe que não haja distinção entre sujeito e objeto da pesquisa, uma vez que toda realidade é representada pelo indivíduo, "toda representação é, portanto, uma forma de visão global e unitária de um objeto. Para que o indivíduo possa formar essa visão global, ele usa elementos de fatos cotidianos e de conhecimentos do senso comum"11:609.

A representação social é expressada como uma "forma de conhecimento socialmente elaborada e compartilhada, com um alcance prático que contribui para a construção de uma realidade comum a um conjunto social" 11:609, onde o sujeito da pesquisa dá sentido a um objeto partindo da rua própria realidade e/ou experiências ${ }^{12}$.

Assumindo que a enfermeira está sendo tomada como sujeito para análise, pressupõe-se que este exercício seja uma reflexão sobre o seu cotidiano de forma a apreender a realidade, que muitas vezes passa despercebida nas atividades diárias.

Para atingir o objetivo proposto neste estudo, foram escolhidos como sujeitos da pesquisa enfermeiras da região sul do Estado de Mato Grosso do Sul, numa microrregião que agrega sete municípios de pequeno e médio porte e que tem como base econômica a agropecuária.

A microrregião de lguatemi está situada no extremo sul do Estado de Mato Grosso do Sul. Os sete municípios que a compõem são de pequeno porte (seis têm menos de 20.000 habitantes). Até 1991, apenas o município de referência (Naviraí) tinha o profissional enfermeiro, que trabalhava na regional de saúde. De 1991 a 1997, duas enfermeiras trabalhavam na rede básica da região, e, a partir de 1999, com a efetiva implantação do Programa de Agentes Comunitários de Saúde (PACS), houve a contratação de enfermeiras em todos os municípios.

Em 1993, a primeira turma de enfermagem foi formada pela Universidade Federal de Mato Grosso do Sul (UFMS), e, em 1997, formou-se a primeira turma de enfermagem da Universidade Estadual de Mato Grosso do Sul (UEMS). Portanto, até então, a maioria dos enfermeiros era oriunda de outras regiões, principalmente do Paraná e São Paulo.

0 campo de trabalho na saúde pública ampliou-se com a implantação do Programa de Agentes Comunitários de Saúde (PACS) e, posteriormente, do PSF, que conta obrigatoriamente com a presença do enfermeiro para a formação da equipe mínima. 
A escolha foi por conveniência, com número definido a partir da obtenção do conteúdo suficiente para compreensão do fenômeno pesquisado. Sendo um estudo comparativo, foi definido que o número de entrevistadas deveria ser pareado, com amostra igual de enfermeiras que atuam em PSF e em Unidades Básicas de Saúde (UBS). Na região escolhida para o estudo, apenas cinco municípios têm os dois modelos de atenção, e isso permitiu que fossem escolhidas uma enfermeira do PSFe uma de UBS, perfazendo uma amostra total de 10 entrevistas.

Em dois municípios dessa mesma região, 0 atendimento é feito $100 \%$ pelo $P S F$, razão pela qual foram excluídos do estudo. Nos cinco municípios restantes, foram entrevistadas cinco enfermeiras inseridas nas Unidades Básicas de Saúde (UBS) e cinco que integram as Equipes de Saúde da Família (ESF).

No primeiro contato, foi explicado o objetivo da pesquisa, apresentando-se o Termo de Consentimento Livre e Esclarecido TCLE, que, depois de lido, foi assinado pelo sujeito, ficando uma via com o entrevistado e outra com o entrevistador. Após assinatura no TCLE, teve início a coleta de dados com a explanação sobre a questão norteadora. As entrevistas foram gravadas e transcritas imediatamente após o seu término e anexadas ao diário de campo, instrumento utilizado para anotações complementares.

Os dados resultantes das entrevistas foram analisados qualitativamente através da técnica do_Discurso do Sujeito Coletivo ${ }^{13}$, utilizando-se três figuras metodológicas: a expressãochave (E-Ch), que revela a essência do depoimento; a idéia central (IC), que é a descrição do sentido presente na expressãochave, e o discurso do sujeito coletivo (DSC), técnica de tabulação e organização de dados qualitativos apresentados através de um discurso síntese, redigido na primeira pessoa do singular e elaborado com os mais significativos extratos de depoimentos de sentido semelhante, presentes nos discursos individuais.

Para chegar ao discurso síntese, foram utilizados os instrumentos de análise de discurso (IAD) 1 e 2. No IAD1, foram transcritas as E-Ch identificadas em cada entrevista, que expressam os eixos definidos para análise. Após esta transcrição, foram destacadas as IC de cada E-Ch. No IAD2, foram agrupadas e transcritas literalmente as $\mathrm{E}$-Ch de todas as entrevistas que se referem às IC destacadas, sendo possível assim formular um DSC para cada IC. Para a formulação do DSC, foram agrupadas as E-Ch de maneira que formassem um discurso coerente. Para tanto, foram utilizados conectores a fim de dar sentido ao DSC sem que isso alterasse a estrutura da frase elaborada pelo sujeito.

0 presente estudo seguiu as Diretrizes e Normas de Pesquisa Envolvendo Seres Humanos ${ }^{14}$, com protocolo de pesquisa apreciado pelo Comitê de Ética de Pesquisa em Seres Humanos da Universidade Federal de Mato Grosso do Sul, que recebeu carta de aceite em 20 de agosto de 2004.

\section{RESULTADOS E DISCUSSÕES PERFIL DAS ENTREVISTADAS}

A média de idade das enfermeiras entrevistadas é de 30 anos. Do contingente pesquisado, $70 \%$ têm menos de quatro anos de formadas, de tempo de trabalho na rede básica e de atuação no local de trabalho atual. Apenas $20 \%$ têm especialização, mas fora da área da saúde pública. Moretto $^{9}$ relata as mesmas características em sua pesquisa com enfermeiros da rede pública no Rio Grande do Sul.

Em relação a treinamentos na área de saúde da mulher ou áreas afins, $70 \%$ das enfermeiras já fizeram algum curso de curta duração. Observa-se que todos esses cursos eram voltados para saúde reprodutiva e ginecologia.

\section{O SENTIDO DA EQUIPE PARA A ENFERMEIRA DA REDE BÁSICA}

\section{Equipe de trabalho}

DSC:

Bom, a nossa equipe é com os agentes, o profissional auxiliar, não temos uma demanda satisfatória, então a nossa equipe é difícil. Ela é incompleta. A minha equipe sou eu e minhas agentes. 0 médico eu posso contar esporadicamente, porque o médico é do centro de saúde. Porque o médico, ele atende e quer sair correndo. 0 médico que está no posto não faz o pré-natal, os exames preventivos são realizados pelos auxiliares, então não tem integração.

A equipe de trabalho é vista pela enfermeira como incompleta, uma vez que nem todos os membros, mesmo presentes fisicamente, compartilham dos mesmos objetivos e da mesma dedicação. Observa-se que existe um afastamento da figura do médico e um maior envolvimento entre a enfermeira e os agentes de saúde, ficando o auxiliar de enfermagem num patamar intermediário. 0 auxiliar de enfermagem é 0 profissional que operacionaliza as tarefas, auxiliando os profissionais de nível superior. A dicotomia entre quem pensa e quem faz aparece claramente no discurso das enfermeiras.

Mesmo quando a equipe se encontra completa, a integração entre seus membros é deficiente.

\section{Atuação conjunta}

DSC:

Difícil, não é o trabalho de equipe, cada um faz o seu serviço, não se senta para discutir dados, para discutir qualidade do que a gente está fazendo, pra ver o paciente que pode no meio do caminho tomar um rumo diferente. A psicóloga, a gente consegue trabalhar junto, porque às vezes está tratando a parte dela, psicologicamente a paciente, daí depois ela diz que a paciente está tomando o remédio tal, com queixa disso, você pode encaminhar para tal lugar. Fisioterapia...só quanto tem uma coisa bem grave que elas passam mesmo pra mim, caso contrário tratam os sintomas. Eu acho que é assim, o velho costume de cada um fazer a sua parte, né? Ela está com uma queixa ginecológica, então não é da minha alçada, né? 0 que dificulta um pouco é a falta de um ginecologista, de um atendimento mais especializado, mas uma referência. A atenção integral? Não leva porque está cada um seguindo o seu caminho, então, não leva. São todos pontos da saúde integral, mas cada um faz do seu jeito e separadamente. Falta preparo da equipe para trabalhar com saúde da 
mulher e entender que saúde integral não é cada um fazer a sua parte. Só que pelo que a gente conversa é mais ou menos assim, só que cada um direciona da sua forma.

Hardinghan ${ }^{15}$ define equipe como um grupo de pessoas que compartilham objetivo(s) que só pode (m) ser atingido(s) pelo esforço contínuo e coordenado de todos os seus membros. Observa-se que mesmo quando a enfermeira diz haver integração na equipe, existe a fragmentação do indivíduo com a prática de encaminhamento para especialistas e a assistência prestada por diversos profissionais dentro de um mesmo espaço sem o mínimo de troca de informação.

Assim, o objetivo comum ${ }^{15}$ não aparece em nenhum momento do discurso das enfermeiras da rede básica. A noção de cooperação mútua aparece na forma de encaminhamentos, e não de discussão de casos.

0 Guia Prático do Programa de Saúde da Família ${ }^{16}$ preconiza que uma equipe seja formada por profissionais de diversas áreas cujas ações possibilitem a reconstrução da prática de um profissional na prática de outro. Essa reconstrução deve observar as características de cada membro da equipe nas atribuições fundamentais da unidade de saúde.

A reformulação das atitudes dos profissionais é colocada como um desafio para a organização do processo de trabalho das equipes ${ }^{17}$, desafio este enfatizado por Schraiber ${ }^{18: 2}$ quando diz que o trabalho em equipe são trocas intersubjetivas e comunicação, em que "cada profissional terá que romper com sua total independência de decisão para compartilhá-la com outros."

A equipe então passa a ser um grupo de pessoas trabalhando juntas, mas cada um desempenhando as suas atribuições profissionais sem a reconstrução preconizada ${ }^{16}$.

\section{Capacitação profissional e o trabalho em equipe}

DSC:

Eu sinto que deveria ter mais treinamento, mais graduação, né? Eles não têm condição de preencher um relatório. A formação profissional influi, porque depois que fizeram mesmo aquele curso de auxiliar já ajudou bastante. Conforme você vai melhorando a formação, você vai atingindo melhores resultados com a equipe que você está trabalhando. Porque, cada vez que vai alguém na capacitação, a gente se reúne para conversar, assim vê que quanto ele volta da capacitação está melhor até para fazer as colocações. Falta preparo da equipe para trabalhar com a saúde da mulher, falta capacitar os profissionais para, se pelo menos um falhar, o outro conseguir pegar, e aíser garantido pelo menos o da mulher.

0 despreparo dos profissionais é colocado como causa de o trabalho do grupo ser feito de forma desarticulada. Esse despreparo está relacionado com o nível educacional dos auxiliares, uma vez que, a cada treinamento ou curso, as enfermeiras observam uma melhora nos resultados das atividades da equipe.

Apesar de não ser explícita, a falta de capacitação dos profissionais de nível superior para lidar com questões cotidianas das dificuldades da população e do trabalho em equipe é evidente. Diversos estudos mostram que a dificuldade está relacionada à formação acadêmica pautada no modelo flexineriano, com forte saber positivista e tecnicista ${ }^{17,18,19}$.

\section{Gerenciamento e equipe ampliada}

DSC:

Eu fiz um treinamento, mas ficou mais pra mim, não cheguei a trabalhar. Acaba que uma pessoa faz o curso, mas quem vai é a pessoa errada. Falta um entendimento até por parte dos gestores, que são despreparados, porque nem todos sabem o que é saúde. A gente tem até uma integração da equipe, falando da experiência desta unidade. Com a secretária de saúde eu até consigo desenvolver bem o trabalho, mas o grande problema do secretário é não entender de saúde. Eles fazem o possível para estar colaborando com a gente, acho que o sistema está... tudo que for necessário eles apóiam, qualquer coisa que venhamos a planejar e nós pedirmos, eles estão prontos para ajudar. Com os agentes é bom, falta algumas coisinhas, vamos fazer uma reciclagem com eles, vamos conversar, vamos fazer um trabalho de treinamento.

As entrevistadas admitem que, mesmo tendo acesso a diversas capacitações, isso nem sempre tem o efeito desejado, já que a pessoa indicada nem sempre assume a responsabilidade pela atividade para a qual foi treinada. Isso ocorre porque ou não gosta do assunto ou porque não tem condições estruturais e/ou cognitivas para exercer a função.

A escolha para participação dos profissionais em cursos e treinamentos oferecidos não é feita pela afinidade e pela disposição em desenvolver as ações propostas, mas sim por outros critérios bastante discutíveis como influências políticas e afinidades pessoais do gestor. Isso acaba levando à nãoefetivação das ações e aos gastos de recursos financeiros sem retorno para a saúde da população.

As enfermeiras entendem que o despreparo atinge todos os profissionais de saúde e os detentores de cargos envolvidos na atenção básica. Os gestores apresentam deficiências na humanização, no conceito de saúde e nas questões de gestão pública, principalmente na administração dos recursos financeiros. Isso dificulta o trabalho dos profissionais da saúde e os desmotiva a implementar ações importantes à promoção da saúde da população.

Quanto à equipe ampliada, que envolve os gestores, observa-se um nítido "apoio" ao trabalho do enfermeiro, mas com limitações por conta do despreparo dos gestores. Entretanto, o planejamento das ações não é feito em equipe, porque cada grupo ou profissional têm o seu planejamento que recebe "ajuda" dos gestores. 0 sentido aqui é que o gestor não faz parte da equipe, mas é apenas o sujeito que fornece meios para que as ações sejam realizadas.

A visão de equipe fica restrita ao grupo de trabalho de cada unidade, de forma que o sistema não se configura como um organismo integrado que deve ter os mesmos conceitos da equipe de trabalho local.

Com os agentes comunitários de saúde, parece haver maior integração, mas ela é sempre vertical, sendo clara a necessidade que eles têm de "reciclagem" e a disponibilidade 
das enfermeiras em fornecer os subsídios que eles não têm para poderem trabalhar.

\section{Humanização}

DSC:

Esta parte da humanização precisa ser trabalhada muito, humanização do atendimento. Eu acho que eles são meio frios quando acolhem a mulher, tentam ajudar, falam, mas são meio frios, falta um quê, que eu não sei explicar o que é.

Minayo ${ }^{20}$ discute o sentido do termo humanização confrontado com a questão da desumanização da assistência à saúde. Os "nós" que travam o processo de humanização são oposição à violência, capacidade de oferecer atendimento de qualidade articulando os avanços tecnológicos, melhoria das condições de trabalho do cuidador e ampliação do processo comunicacional2 ${ }^{21}$. O DSC está voltado para esse último sentido; entretanto, as enfermeiras não conseguem identificar o que falta para que esse processo se dê de forma a melhorar o que Mattos ${ }^{22}$ define como "operação de resgate das relações". Apesar do termo humanização aparecer apenas neste trecho do DSC, a necessidade de humanização do atendimento influencia no desenvolvimento do trabalho da equipe, sendo essencial 0 entendimento de todos os sentidos desse conceito ${ }^{21}$.

Desta forma, é preciso que os profissionais aprendam a escutar, acolher, respeitar e dar resposta às demandas femininas.

\section{Espaço de atuação}

DSC:

Assim como eu citei que a equipe é boa, o médico é bom, mas eu vejo que ele também não quer perder o espaço dele. Só que ele podia ter dado uma abertura pra mim. Porque também ele vai pensar assim: eu vou ficar fazendo o que aqui no posto? E aí eles não conversam entre si, a própria classe é desorganizada, mesmo eles sendo desorganizados, eles são muito unidos. Na minha opinião, eles não aceitam muito o que a gente... Aqui ninguém está querendo passar por cima de ninguém, eu acho já seria melhor... é trabalhar em grupo. Mas (risos)... é difícil, principalmente com a classe médica. Infelizmente o meu médico acha que a figura dele na equipe é muito mais importante que qualquer outro profissional, o meu médico não ajuda, na emergência ele me dá autonomia também de estar colocando, avaliando a necessidade de realmente passar com urgência, daí eu vou estar conversando e ele atende. Assim, a parte médica, a gente sempre entra em contradição, não tem como, né? Aqui quem não se envolve para poder falar que o PSF realmente funciona é o médico.

A disputa de poder e espaço entre profissionais, principalmente médicos e enfermeiros, aparece como obstáculo para o trabalho em equipe se concretizar. A hegemonia médica é observada por Prado ${ }^{23}$ referindo-se tanto a questões numéricas quanto às de gênero, uma vez que os médicos são na maioria das vezes do sexo masculino, enquanto as enfermeiras e auxiliares são do sexo feminino. No grupo entrevistado, não existe nenhuma médica e nenhum enfermeiro, confirmando os estudos sobre gênero na saúde e sobre as características das equipes de saúde ${ }^{23}$.

Neste sentido, nota-se uma ansiedade por parte das enfermeiras em mostrar sua capacidade técnica, estando também implícito no seu discurso o fato de que o médico é uma figura importante já que ele pode "dar uma abertura", "não aceita muito a gente", "me dá autonomia". Araújo et al. ${ }^{24}$ discutem que os profissionais utilizam o saber como forma de poder e o senso comum elege o médico como detentor de todo o conhecimento.

Quando a enfermeira é colocada como "auxiliar de médico" 25 , identifica-se a origem da dominação médica sobre os demais profissionais de saúde, evidenciando a relação de subordinação que existe entre médicos e enfermeiras.

A formação acadêmica, segundo estes mesmos autores, faz com que a enfermeira não esteja preparada para disputar espaço com o médico.

A indefinição do espaço de atuação dos membros da equipe também é marcante. Provavelmente, a mudança que o PSF propõe ainda não foi incorporada pelos profissionais que trabalham na lógica de cada um em seu espaço. Isso gera uma constante contradição entre os profissionais em diversas questões relativas à saúde da mulher. Eles ainda não aprenderam a construir consensos, o que leva a falhas no funcionamento do PSF.

\section{Equipe}

DSC:

Parece que tudo tem que ser o enfermeiro começar, todos os programas; se o enfermeiro não dá o pontapé inicial o programa não vai. Eu tenho um trabalho muito bom, então eu já consegui que eles tenham o meu pensamento. Eu faço, eu trabalho de uma maneira e outro enfermeiro pode trabalhar de outra forma. Então tudo o que se vai decidir, nós (enfermeiras) decidimos juntas. A gente procura se reunir e discutir esses assuntos. No que a coordenadora vai decidir, ela não está sozinha, ela convida todas; a gente faz uma reunião, e vale a idéia, e a gente fecha com as idéias de todas. Mas na verdade não acaba sendo PSF. Quem faz o papel de PSF são os enfermeiros, os médicos não.

Existe ainda a certeza de que a enfermeira está sempre sendo responsabilizada por todas as ações. A enfermeira deve ser uma líder nata, mas isso reflete no grupo como um comando, um direcionamento. Inclusive quando elas referem ao planejamento em grupo, esse é feito no grupo de enfermeiras. Elas conseguem chegar a um acordo, mas com os médicos essa relação tende a ser conflituosa.

O DSC ressalta os diversos aspectos que configuram as falhas da equipe, mas demonstra também que a culpa nunca é da enfermeira. Parece que ela está preparada para o trabalho em equipe, mas os outros membros não. Em nenhum momento aparece a definição clara do que seja um trabalho em equipe.

A interdependência e a interação entre os membros da equipe para melhorar os resultados das ações propostas e dos objetivos definidos não ocorrem na visão das enfermeiras entrevistadas. $\mathrm{Na}$ realidade, observa-se que este nível de interação sequer é possível na etapa de desenvolvimento em que se encontram as equipes da região. 
Nos discursos, observa-se uma dissociação de objetivos entre os diversos membros da equipe, enfatizada pelo fato de que "cada um faz a sua parte", não havendo, portanto, motivação para um trabalho integrado.

A comunicação é prejudicada por fatores como a disputa de espaço/poder dentro e fora da equipe, dificultando, inclusive, o relacionamento interpessoal no grupo e deste com a população atendida.

0 processo decisório, ao contrário de ser construído coletivamente, é feito de forma individual, geralmente pautado nas técnicas desenvolvidas por cada profissional. Desta forma, não se tem uma liderança orientada para a participação e for talecimento do próprio grupo.

Assim, o desempenho do grupo não é satisfatório, porque as atividades são planejadas e executadas individualmente. Sabe-se que este tipo de planejamento não estimula a motivação e a inovação.

A enfermeira, por mais que insista em dizer que tem um trabalho em equipe, demonstra, em seu discurso, que o trabalho é todo desenvolvido de forma fragmentada, individualizada, pois cada profissional se envolve, somente, com as suas funções técnicas. Mesmo a enfermeira apresenta um discurso individual, centrado no seu trabalho, ao demonstrar um estilo de liderança voltado para o controle/tarefa ${ }^{10}$. Este estilo pode também ser chamado de participativo, no qual a enfermeira dialoga e faz sugestões, mas retém a decisão final e 0 direcionamento das tarefas a serem realizadas.

Esta liderança está mais relacionada à parte burocrática do trabalho do grupo que propriamente à capacidade de liderar da enfermeira, uma vez que dentro do grupo, em geral, é a enfermeira que tem a responsabilidade pelo controle de todos os dados produzidos pelo serviço. Para tanto, é ela também quem faz os planejamentos e as negociações para a realização das ações, tanto com a equipe e a instituição como com a comunidade.

\section{Referências}

1. Ministério da Saúde (BR). Manual para a Organização da Atenção Básica. Brasília (DF); 1998.

2. Teixeira CF, Paim JS, Vilasboas AL. SUS: modelos assistenciais e vigilância da saúde. Inf Epidemiol SUS 1998 abr/jun; 2: 7-28.

3. Ministério da Saúde (BR). Agentes comunitários de saúde, equipes de saúde da família e equipes de saúde bucal em atuação. Competência jun/2004. [on-line] 2004 set; [citado 10 set 2004]; Disponível em: http://www.portal.saude.gov.br/saúde/arquivos/pdf/ planilha_agosto_2004.pdf.

4. Ministério da Saúde (BR). Política Nacional de Atenção Integral à Saúde da Mulher: princípios e diretrizes. Brasília (DF); 2004.

5. Pinto CMF, Luiz OC. Atenção integral no PSF: a saúde da mulher. [online] 2004 jun; [citado 21 jun 2004] Disponível em http:// www.fmrp.usp.Br/resum/congresso/pagina/ANAIS/ $272 \% 20 \%$ Catherine.\%20m\%20F\%20pinto.doc.

\section{CONSIDERAÇÕES FINAIS}

As representações sociais das enfermeiras da rede básica de saúde apontam para uma visão fragmentada da assistência à saúde da mulher. A formação acadêmica é um dos fatores preponderantes na fragmentação das práticas, enfatizado pela dificuldade dos profissionais em desenvolver o trabalho em equipe. 0 próprio entendimento do conceito de equipe, para a enfermeira, é baseado no trabalho de diversas especialidades para uma mesma clientela, mas com dificuldades de interação e sem compartilhar dos mesmos objetivos.

A reformulação dos projetos pedagógicos dos cursos de formação na área de saúde, de acordo com a Lei de Diretrizes e Bases da Educação (Lei 9394/96), recomenda a ação prioritária para as universidades, no sentido de minimizar os problemas referentes à formação acadêmica desses profissionais, em especial nos assuntos ligados ao trabalho em equipe.

Em relação à capacitação de recursos humanos no SUS, observa-se que também é fragmentada, baseada em faixas etárias, grupos específicos ou grupos profissionais, o que sedimenta a dificuldade de integração entre profissionais e formação de equipes, conforme conceituado por Moscovici ${ }^{10}$.

A falta de integração leva também à falta de socialização de informações e conhecimentos adquiridos nas capacitações proporcionadas pelo Estado, Prefeituras, Ministério da Saúde e outros órgãos.

A mudança da prática assistencial de todos os profissionais envolvidos na assistência à saúde da mulher pode ser proporcionada a partir das mudanças conceituais e paradigmáticas na formação básica e na educação continuada, bem como nas propostas de políticas públicas para o setor de capacitação em saúde.

Assim, as mudanças ocorrerão quando conseguirmos alterar as representações sociais dos profissionais envolvidos, o que pressupõe um processo amplo de mudança de discurso, de comportamento e de atitude de cada profissional e do grupo que assiste a mulher, bem como no conceito de saúde da população.

6. Silva EM, Nozawa MR, Freitas JLD. Formação de enfermeiros e a municipalização da saúde no Brasil: a importância das políticas e das práticas. Rev Bras Enferm 2000 abr/jun; 53 (2): 275-82.

7. Barrientos DMS. Mulher e saúde: dialetizando o trabalho da enfermagem ambulatorial [tese de doutorado] Ribeirão Preto (SP): Escola de Enfermagem de Ribeirão Preto/USP; 2002.

8. Schraiber LB. Desafios atuais da integralidade em saúde. Jornal da Rede Feminista de Saúde [on-line] 1999 maio; [citado 04 ago 2003]; 17. Disponível em http://www.redesaude.org.br/jornal/html/ jr17_desafios.html.

9. Moretto ES. Os enfermeiros e o SUS: da realidade à possibilidade. Passo Fundo(RS): UPF; 2001. Série dissertações. Enfermagem, 7.

10. Moscovici F. Desenvolvimento interpessoal: treinamento em grupo. $13^{\mathrm{a}}$ ed. rev. ampl. Rio de Janeiro(RJ): J Olympio; 2003.

11. Oliveira DC, SÁ CP. Representações sociais da saúde e doença e implicações para o cuidar em enfermagem: uma análise estrutural. Rev Bras Enferm 2001 out/dez; 54(4): 608-22. 
12. Costa WA, Almeida AMO. Teoria das representações sociais: uma abordagem alternativa para se compreender o comportamento cotidiano dos indivíduos e dos grupos sociais. Rev Educ Publica [on-line] 1999 jun/dez; [citado 22 out 2003]; 7 (13). Disponível em: http://www.ufmt.br/revista.html.

13. Lefèvre F, Lefèvre AMC. 0 discurso do sujeito coletivo: um novo enfoque em pesquisa qualitativa (desdobramentos). Caxias do Sul (RS): EDUCS; 2003.

14. Ministério da Saúde (BR). Conselho Nacional de Saúde. Diretrizes e normas regulamentadoras de pesquisas envolvendo seres humanos. Resolução CNS nº 196, de 10 de outubro de 1996. Inf Epidemiol SUS 1996; 5 (2 supl 3): 13-41.

15. Hardonghan, A. Trabalho em equipe. São Paulo: Nobel; 2002.

16. Ministério da Saúde (BR). Guia prático do programa de saúde da família. Brasília (DF); 2001.

17. Mendonça CS, Sampaio LFR, Lima PGA. Saúde da família: avanços, desafios e perspectivas. Rev Bras Saude Familia. 2002 maio; 5: 66-9.

18. Campos FE, Cherchiglia ML, Aguiar RAT. Reflexões sobre a saúde dafamiliano Brasil: desafios e oportunidades. Rev Bras Saude Familia. 2002 maio; 5: 70-3.
19. Santos BRL, et al. Formando o enfermeiro para o cuidado à saúde da família: um olhar sobre o ensino de graduação. Rev Bras Enferm 2000 dez; 53 (n. esp): 49-59.

20. Minayo MCS. Dilemas do setor saúde diante de suas propostas humanistas. Cienc Saude Col 2003; 9(1): 17-20.

21. Deslandes SF. Análise do discurso oficial sobre a humanização da assistência hospitalar. Cienc Saude Col 2004; 9 (1): 7-14.

22. Mattos RA. Os sentidos da integralidade: algumas reflexões acerca de valores que merecem ser defendidos. In: Pinheiro R, Mattos $R A$,organizadores. Os sentidos da integralidade na atenção e no cuidado à saúde. Rio de Janeiro (RJ): ABRASCO; 2001.

23. Prado N. Profissões de saúde: profissões de mulher? Cad FUNDAP 1985 jul; 5 (10): 44-56.

24. Araújo CLF, Gomes SRC. Práticas e políticas de saúde como determinante do papel social da mulher. Esc Anna Nery Rev Enferm 1997; 1 (1): 49-57.

25. Stacciarini JMR, et. al. Quem é o enfermeiro. Rev. Eletr Enferm [periódico on- line] 1999 out/dez; [citado 30 jul 2003]; 1(1). Disponível em: www.fen.ufg.br/revista. 